\title{
Using new artificial bee colony as probabilistic neural network for breast cancer data classification
}

\author{
Habib Shah \\ Department of Computer Science, College of Computer Science, King Khalid University, Abha, Saudi Arabia
Department of Computer Science, College of Computer Science,

\section{Probabilistic neural network for breast cancer classification}

\begin{abstract}
Purpose-Breast cancer is an important medical disorder, which is not a single disease but a cluster more than 200 different serious medical complications.

Design/methodology/approach - The new artificial bee colony $(\mathrm{ABC})$ implementation has been applied to probabilistic neural network (PNN) for training and testing purpose to classify the breast cancer data set.

Findings - The new ABC algorithm along with PNN has been successfully applied to breast cancers data set for prediction purpose with minimum iteration consuming.

Originality/value - The new implementation of $\mathrm{ABC}$ along PNN can be easily applied to times series problems for accurate prediction or classification.
\end{abstract}

Keywords New implementation of ABC, Probabilistic neural network, Breast cancer classification

Paper type Research paper

\section{Introduction}

Currently, the world is facing coronavirus, which has infected more than a billion people and killed millions. Despite the vaccine rollout, millions are still in critical condition and infection rates are rising. Deadly viruses, including human papillomavirus (HPV), hepatitis C, human herpes virus 8 (HHV-8), human T-lymphotropic and human immunodeficiency (HIV), have existed since $3000 \mathrm{BC}$ in animals and humans (Chigbu et al., n.a.; Shah et al., 2016; Mui et al, 2017). Molluscs, fish, ants, bees, reptiles, birds, cows, buffaloes, lions and other wild and domestic animals are susceptible to viruses (Pervanidou et al, 2020). Cancer affects much of the human population, regardless of specific circumstances, including weather and culture (Vaisitti et al, 2020), often leading to critical conditions and death, despite rigorous treatments such as chemotherapy. The most common types of cancers include colorectal cancer, nonHodgkin lymphoma, lung cancer, prostate cancer, breast cancer (BC), kidney cancer, endometrial cancer, leukemia, pancreatic cancer, melanoma, bladder cancer, thyroid cancer and liver cancer (Sung et al, 2021). Of over 200 different types of risky cancers that have been identified in the human body, blood, bones and cells, BC is diagnosed with the greatest frequency in the USA and has been identified as the most common cancer in women. Based on the data set, BC is existing in 158 as shown in Figure 1 (69,372 Lyon CEDEX 08, 2020).

According to the World Health Organization (WHO), cancer has killed millions of people around the world as shown in Figure 2 (WHO, 2020). Globally, BC represents one in four

\footnotetext{
(C) Habib Shah. Published in Frontiers in Engineering and Built Environment. Published by Emerald Publishing Limited. This article is published under the Creative Commons Attribution (CC BY 4.0) licence. Anyone may reproduce, distribute, translate and create derivative works of this article (for both commercial and non-commercial purposes), subject to full attribution to the original publication and authors. The full terms of this licence may be seen at http://creativecommons.org/licences/by/4.0/legalcode

The author would like to thank the College of Computer Science, King Khalid University, Kingdom of Saudi Arabia, for providing research facilities and resources. In addition, the author appreciates the reviewer's valuable comments for improving the quality of the research article.
} 


\section{FEBE}

1,2

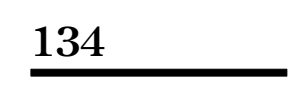

Figure 1.

Most common cancer cases (2018) report by WHO

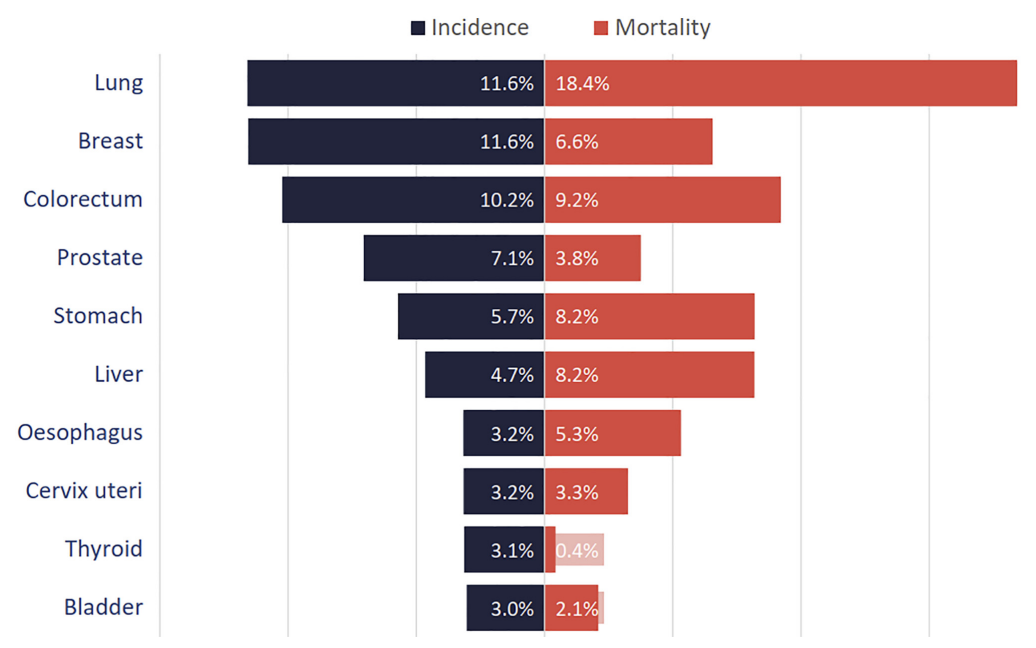

Source(s): GLOBOCAN IARC (http://gco.iarc.fr/today) World Health Organization

cancers diagnosed among women. The other most common cancers in women are lung, colorectal and thyroid. Bladder, colon, pancreatic, prostrate and rectal, melanoma and non-Hodgkin lymphoma were present in $37.8 \%$ of women in 2020 (Quist et al., 2021). According to the $2020 \mathrm{WHO}$ annual report, globally in 2018 there were an estimated $18,078,957$ cases of the most common cancers and those 9,555,027 patients died out of an estimated 7,676,965,500 as shown in Figure 1.

All existing pandemic disease predictions are very important as they provide future indicators, warnings, data and deep knowledge for medical experts, patients, governments and top health establishments to manage the potential and present risk factors and can support different stakeholders and save lives, businesses and futures. Computer science tools based on artificial intelligence (AI) are famous for solving complex and uncertain problems both in real and artificial life. There are so many AI famous methods including heuristics, ANN (Artificial Neural Networks), support vector machines, natural language processing and Markov decision process (McNelis, 2005; Neapolitan, 2018; Agarwal et al., 2019; Naeem et al., 2020).

In the last 20 years, researchers have become more interested in developing, improving and applying bio-inspired algorithms after a successful typical heuristic performance. ANN is trained by bio-inspired learning algorithms such as ant colony optimization (ACO), cuckoo search algorithm (CSA), bat algorithm (BA) and the improved versions of various bio-inspired learning algorithms (Yang, 2010, 2014; Bullinaria and AlYahya, 2014; Chen et al., 2014; Punitha et al., 2021). The original type of artificial bee colony (ABC) has been successfully applied to resolve classification and prediction problems. Here, the new version of the $\mathrm{ABC}$ algorithm is proposed to train probabilistic neural network (PNN) to obtain highly accurate results in $\mathrm{BC}$ classification data sets.

The rest of this research paper is prepared as follows. BC is briefly explained in section 2 , along with its prediction tools. Sections 3, 4 and 5 present an overview of ANN, optimization learning algorithms and training PNN by combining new implementation $\mathrm{ABC}$ algorithm with experimental design. Simulations results and conclusions are given in sections 6 and 7 .

\section{Breast cancer prediction}

$\mathrm{BC}$ is a serious medical disorder that can occur in both men and women and is part of the cluster of risky diseases caused by the various types of virus, infections and disabilities 


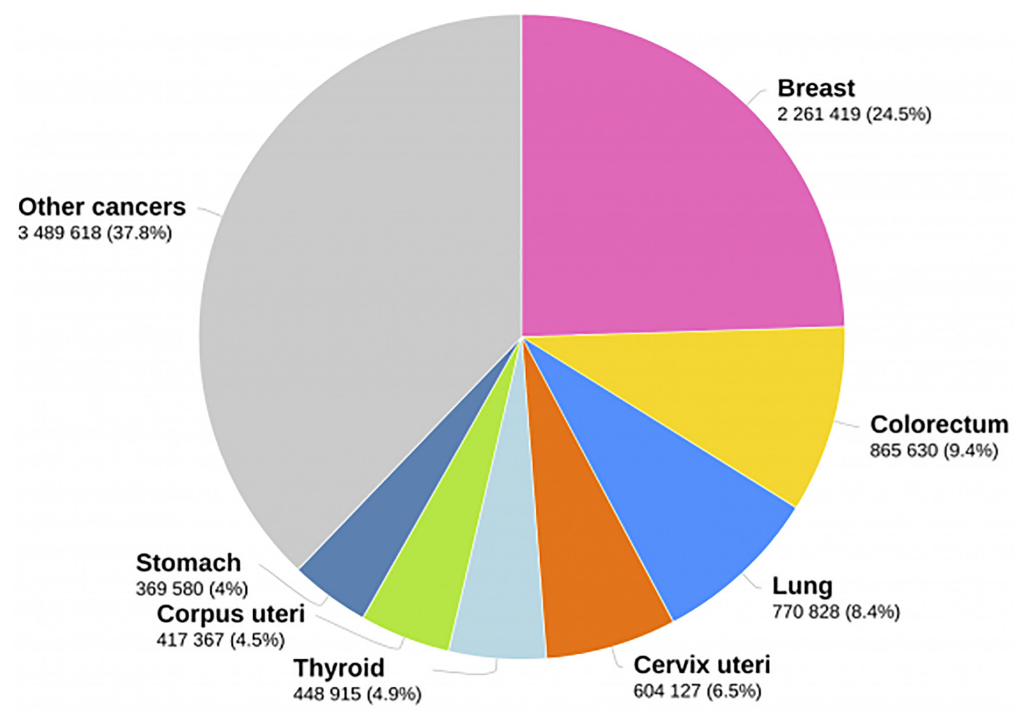

\section{Probabilistic neural network for breast cancer classification}

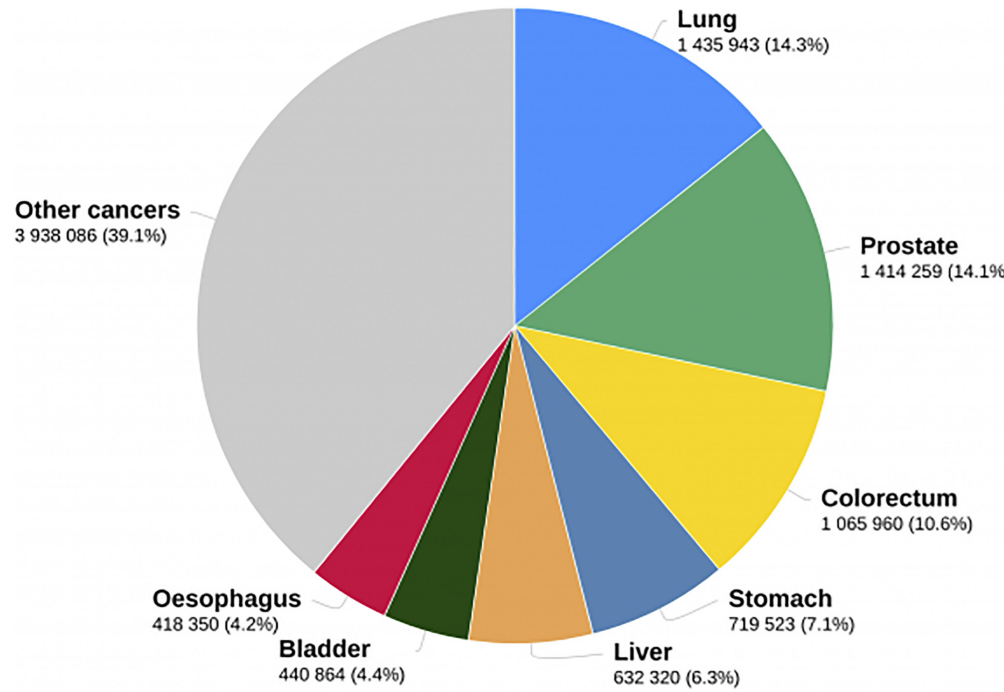

Figure 2.

Estimated number of new cancer cases in 2020 , in females and males respectively, all ages

(Society, 2019). Internally, breasts in men and women have similar fatty tissue, cells and ducts; some patients have inherited mutations in BRCA1 and BRCA2 genes and produce estrogen that may cause an increase in cancer risks. $\mathrm{BC}$ is common in women because during puberty they develop working lobules and milk ducts (that connect the lobules to the nipple) to produce and carry milk after childbirth, and $\mathrm{BC}$ can develop in these ducts and lobules, which are not produced by men (Nishiyama et al., 2020). BC leads to the increase in abnormal cells and destroys normal body tissue and can lead to disability and death. BC refers to any malignant tumor where the pattern of growth of cancer cells often resembles a twisted and distorted version of the tissue that is arising. Any changes in the size or the shape of the 
FEBE 1,2 breast, spontaneous discharge (especially if bloody), scaliness, retraction and thickening or swelling of part of the breast can be a sign of BC (Nagao et al., 2003).

The most important challenge in addressing $\mathrm{BC}$ is the effectiveness of the treatment, especially in early and middle stages, which can be handled positively based on an accurate early prediction (Gray et al., 2018), and BC patient mortality rate can be reduced significantly with an accurate BC diagnosis (Islam et al., 2020). This is why researchers from various fields are working on the classification, prediction and diagnosis of cancers. Different computational, noncomputational, analytical and advance medical tools are used to diagnose, detect and classify the level, source and intensity of early $\mathrm{BC}$, and $\mathrm{AI}$ techniques are utilized to predict $\mathrm{BC}$ timeline with diagnoses. Magnetic resonance imaging (MRI), X-ray and cathode ray tube (CRT) images have been used for nearly 27 years in addition to newer analytical techniques for diagnosing BC (Asri et al., 2016; Islam et al., 2020).

AI tools such as support vector machine, PNN, other types of ML are simulated and results compared when doctors are choosing the ideal highly accurate classification method for $\mathrm{BC}$ detection and staging (Ayer et al., n.a.; Suruchi, 2016; Supriya and Deepa, 2020). To get the highly accurate simulation results for $\mathrm{BC}$ classification in this paper, the four mentioned metaheuristic algorithms are used and the results compared, which are explained in section 4 and 5.

\section{Artificial neural networks with bio-inspired algorithms}

ANN and metaheuristics learning algorithms are prominent due to their high accuracy rates, dynamic methods of solving complex problems and for using attractive behaviours of swarms and other insects for algorithms such as bat algorithm, cuckoo search algorithm, African buffalo algorithm, ant colony algorithm, bees algorithm, bacterial foraging algorithm, as well as hybrid and improved versions (Karaboga and Akay, 2009; Teodorović, 2009; Yang, 2010; Mernik et al., 2014). These methods are the most wellregarded and attractive algorithms based on various nature-inspired seen and unseen behaviours. These methods are not only well known based on their inspired perceptions, discoveries, actions and understanding, but primarily for their effective and efficient results during the solution of complex and very complex science and engineering problems. ANN, in the form of simple biological and artificial neurons, is a prominent and the active division of ML research used for solving complex, science, engineering, probabilistic and linear and nonlinear problems; many cancers are difficult to learn, perceive and understand from previous patterns, and so to use prior testing and validation for the classification of the innovative trends among them is helpful (McCulloch and Pitts, 1943; Zhang et al., 2015).

The most important relationship between the bio-inspired learning algorithms and neural networks types such as MLP is "that ANN can outperform and solve the complex problem with the support and guidance of robust algorithms in training, testing and validations phases" (Ghazali et al., 2008; Shah and Ghazali, 2011; Hu et al., 2012; Waheeb et al., 2016). So, if the learning algorithms have correctly trained the network, then the best solution can be obtained in a reasonable time and using available resources. In this regard, based on the previous published research progress, bio-inspired algorithms, especially from $\mathrm{ABC}$, have successfully trained neural networks for hard complex problems. Here, the neural network $\mathrm{PNN}$ has been trained by the new implementation of the $\mathrm{ABC}$ algorithm on $\mathrm{BC}$ data sets. The architecture of PNN is given as: (see Figure 3, Specht, 1992) .

The PNN will be trained and tested by using the new implementation of ABC, GABCS, guided $\mathrm{ABC}$ and new $\mathrm{ABC}$ algorithms for finding the best weight values to produce the correct classification of the BC data set as it has been applied successfully before to MLP (Karaboga et al., 2007). 

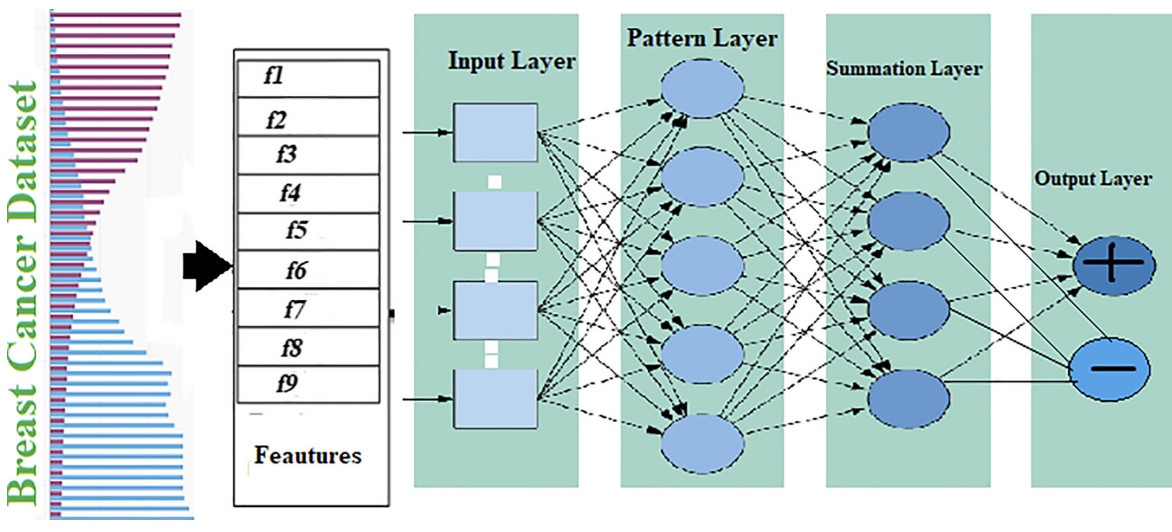

Probabilistic neural network for breast cancer classification

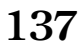

Figure 3.

Probabilistic neural network architecture for the classification of $\mathrm{BC}$

\section{The proposed method: new implementation of $\mathrm{ABC}$ algorithm}

Researchers around the world, from the specific to the general, are working to solve the complex problems using the correct and advanced methods. It was found that metaheuristic algorithms, especially the latest bio-inspired methods, are well regarded due to their high success rate compared to other typical methods. $A B C$ is one of the attractive bio-inspired algorithms, which has been successfully applied to various issues after it was developed in 2005 for effectively solving benchmarked difficult numerical optimization problems. In 2007 , the ABC algorithm was successfully applied to train, test and validate ANN for Boolean classification problems (Karaboga et al., 2007; Karaboga and Gorkemli, 2011), and afterward the $\mathrm{ABC}$ was applied to many time series analysis, classification, prediction and optimization problems (Tairan et al., 2019). The original or typical version of $\mathrm{ABC}$ has been improved by various researchers in different ways such as guided, local best, global best, current best, quick, hybrid-guided and an estimated 2,000 improved versions in different applications (Zhu and Kwong, 2010; Akay and Karaboga, 2012; Gao et al., 2012). In 2017, the standard ABC was improved and implemented by solving optimization problems of CEC,12 (Mernik et al., 2014). This improvement and implementation are referred to as the new implementation of $\mathrm{ABC}$ algorithms. The new $\mathrm{ABC}$ can be explained in four phases: initialization phase, new employed bees phase, new onlooker bees phase and new scout bees phase. Each phase is individually explained in the following sections.

\subsection{Various phases of new $A B C$ algorithms}

In the initialization of the new $\mathrm{ABC}$ algorithm, the total population, colony size and limits, which are the main control parameters, are set. The bee population consists of two groups (new employed bee phase and new onlooker bee phase), which are equal to each other in number. In this proposed research method, half of the $\mathrm{ABC}$ population consists of the new employed bee phase, and the other half includes new onlooker bee phase. The new onlooker artificial bees stay in the hive and decide on obtaining FS to be utilized based on information shared by the new employed group by using the typical exploitation equation. The new scout bee phase has two ways for finding optimal food sources, either by randomly searching the possible space or detecting possible outside signs. In the early phase of the searching process, the bees start to discover the best food source location in the environment randomly (Mao et al., 2016). After finding a food source, which can be evaluated by the fitness functions, the current bee groups become new employed foragers and jump to discover the best food 
FEBE 1,2 sources in the specified areas. The new employed bees individually return to the hive with the optimal nectar amount and quantity and drop the best findings in the hive. After dropping the best nectar into the hive, the new employed bee groups will start searching again to discover the best food source areas by dancing in the designated dancing area. The new employed bee groups can become the new scout bees if the obtained sources are exhausted. Therefore, the new employed bees will start searching randomly, based on different route selections, for finding the best sources as well. The new onlooker bees wait in the nest to watch the dances advertising the profitable sources and choose a source site depending on the frequency of a dance proportional to the quality of the source.

In the new implementation of $\mathrm{ABC}$ algorithm, the new employed bees are responsible for exploiting the nectar sources and giving information to the waiting bees (new onlooker bees) in the hive about the quality of the food source sites they are exploiting. Based on the new $\mathrm{ABC}$ implementation, replacing the stopping criteria maximum cycle number (MCN) with the maximum number of fitness evaluations (MFE) and by counting FE dynamically (during a new $\mathrm{ABC}$ run) in the function calculate fitness 0 used the in new $\mathrm{ABC}$ phases: initialization, new employed bee phase, new onlooker bee phase and new scout bee phase. In addition, when the new employed bee phase reaches the best food and becomes a new scout bee, it does not devour a $\mathrm{FE}$ in the new employed bee section by randomly replacing the solution, so the number of $\mathrm{FE}$ per iteration will be $2 * \mathrm{SN}$. The new implementation of $\mathrm{ABC}$ pseudocode is:

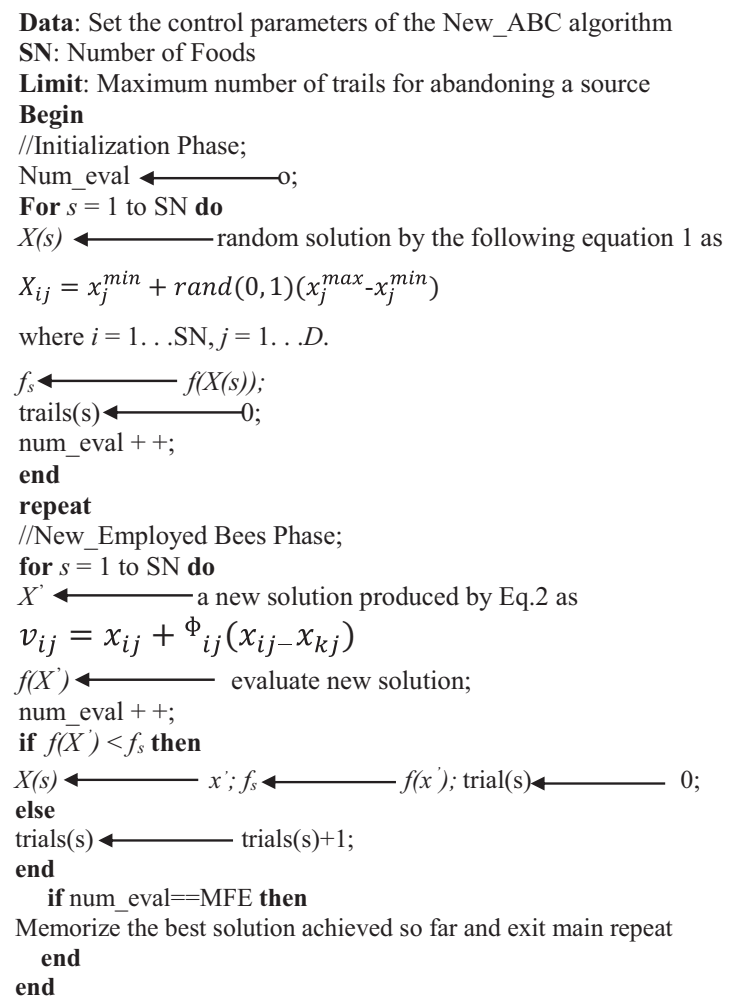


Calculate the probabilities values $P i$ for the solution using fitness values by eq 3 and 4 as

$$
p_{i}=\frac{f i t_{i}}{\sum_{k=1}^{S N} f i t_{n}}
$$

The calculation of fitness values of solutions can be obtained by the give formula as,

$$
f i t_{i}= \begin{cases}\frac{1}{1+f i t_{i}} & f_{i}>=0 \\ 1+a b s\left(f_{i}\right) & f_{i}<0\end{cases}
$$

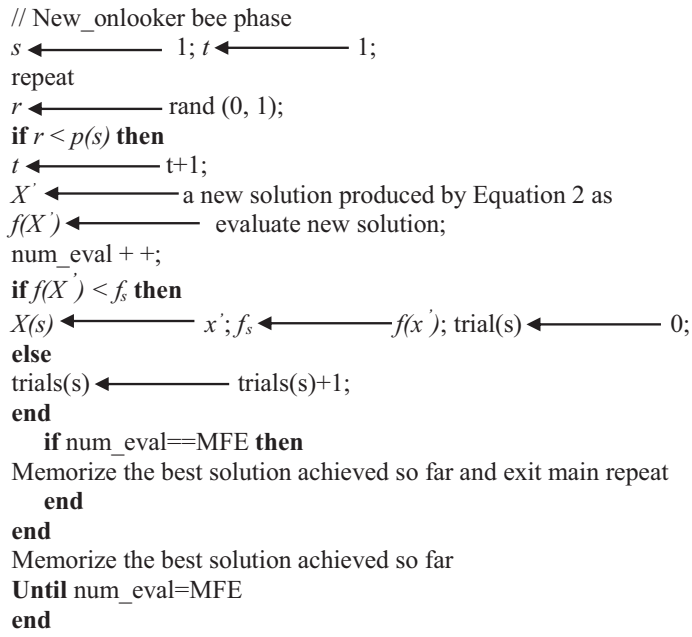

Probabilistic neural network for breast cancer classification

The typical $\mathrm{ABC}$ algorithm, which is based on $\mathrm{MCN}$, has also obtained the best output during the solving of optimization and engineering problems when compared to other bio-inspired computation algorithms. However, the old $\mathrm{ABC}$ algorithm can be further improved to obtain a robust performance with sophisticated search equations, based on fair comparison of control parameters and suitable stopping conditions. Therefore, based on the new implementation of $\mathrm{ABC}$ algorithm, which is time saving and does not consume allowed iterations, it has been presented to overcome the previous problems.

\section{Experimental design}

The PNN performance for various data sets either univariate or multivariate classification and prediction tasks purely depends on different methods, such as the selection of the appropriate PNN topologies, input and output patterns and their nature, suable activation function, nature of the training and testing data set, initial and range of weight and bias values, types of data set and, most importantly, the stopping criteria and learning algorithms. Therefore, if the abovementioned issues are adjusted correctly, PNN can also obtain highly accurate simulation results on classification tasks in different domains. For selecting the best choice of the above, this section explains the experimental design setting of parameters, which included the management of the $\mathrm{BC}$ data set, variable selections, data set preprocessing with partitioning, PNN network structure, the newly proposed and typical bioinspired algorithms, model selection and performance metrics. Here, the old implementation of $\mathrm{ABC}$ algorithm, global artificial bee colony search algorithm (GABC), guided artificial bee 
FEBE

1,2

140

colony algorithm $(\mathrm{GABC})$ and the new implementation of $\mathrm{ABC}$ algorithm are explained with their required and corresponding parameters to simulate $\mathrm{PNN}$ for $\mathrm{BC}$ classification tasks.

In this research article, four types of $\mathrm{BC}$ data set from UCI have been used for classification tasks and include the years 1992, 1995 and 2018 from different patients and areas (Soklic, 1994; Patrício et al., 2018). The features of BC Coimbra data set for 1995 were observed and measured 64 patients with $\mathrm{BC}$ and 52 healthy controls. The Wisconsin data set contained 400 records selected for classification purpose, with nine attributes such as single epithelial cell size, clump thickness, single epithelial cell shape, marginal adhesion, uniformity of cell size, bare nuclei, normal nucleoli, bland chromatin and mitoses. While the Madison and Patricio data sets contain different parameters such as age (years), BMI $(\mathrm{kg} / \mathrm{m} 2)$, glucose $(\mathrm{mg} / \mathrm{dL})$, insulin $(\mu \mathrm{U} / \mathrm{mL}), \mathrm{HOMA}$, leptin $(\mathrm{ng} / \mathrm{mL})$, adiponectin $(\mu \mathrm{g} / \mathrm{mL})$, resistin $(\mathrm{ng} / \mathrm{mL})$ and MCP-1 $(\mathrm{pg} /$ $\mathrm{dL}$ ) with two classes: a healthy control and a patient. The PNN was trained and evaluated using typical simulation ratio with $70 \%$ for training and $30 \%$ for testing purposes, respectively. Accuracy measurements, such as root mean square error (RMSE), mean absolute error (MAE), mean square error (MSE) and success rate, were calculated and defined by the classification error through the Matlab 2017 by Lenovo core i7, 12 Gb RAM. The stopping criteria for old $\mathrm{ABC}$, global $\mathrm{ABCS}$ and guided $\mathrm{ABC}$ algorithms were maximum cycle number $(\mathrm{MCN})$ of 3,000, while the new $\mathrm{ABC}$ was stopped based on the MFE.

\section{Simulation results}

For the classification of $\mathrm{BC}$ simulation results and result analysis, the evaluation of each of the abovementioned (old $\mathrm{ABC}, \mathrm{GABCS}$ and $\mathrm{GABC}$ and new $\mathrm{ABC}$ ) algorithms used for the four types of $\mathrm{BC}$ data sets is performed. The average experimental simulation results above for four metaheuristic algorithms based on Table 1 settings and different criteria for $\mathrm{BC}$ classification are given in Tables 2-4. Every PNN architecture was simulated, along with four proposed and typical algorithms, with five trails and the average of each probabilistic network structure with other parameters and their corresponding outputs is calculated with the training and testing MSE, RMSE and success rate for finding the effectiveness of the four mentioned metaheuristics algorithms.

In Tables 2 and 3, the best average simulation results in terms of MSE training and testing for $\mathrm{BC}$ classification are discussed. The RMSE values for $\mathrm{BC}$ classification are given in Table 4 with different topologies, where the new $\mathrm{ABC}$ learning algorithm reaches success points with the least RMSE values when compared with other algorithms' progress. In the case of proposed new $\mathrm{ABC}$ and typical GABCS algorithms, the performance in the training and testing steps became stable with very minor classification errors.

In Table 2, the MSE training through the proposed new $\mathrm{ABC}$ and GABCs is less than the MSE from old $\mathrm{ABC}$ and guided $\mathrm{ABC}$ algorithms with $\mathrm{PNN}$. In addition, the new $\mathrm{ABC}$ method obtained the outstanding MSE rather than the other three bee-based learning algorithms in both training and testing phases. The abovementioned four bio-inspired training methods

Table 1.

Parameter setting for metaheuristic learning algorithms to train PNN

\begin{tabular}{lcccc}
\hline Parameters & Old ABC & GABCS & GABC & New ABC \\
\hline Number of food sources (FS) & 20 & 20 & 20 & 20 \\
Maximum cycle numbers (MCN) & 3,000 & 3,000 & 3,000 & 3,000 (MFE) \\
$\mathrm{C}_{1}$ & N/A & 1.2 to 1.5 & N/A & N/A \\
$C_{2}$ & N/A & 1.2 to 1.6 & N/A & N/A \\
Upper bound (UB) & $10-20$ & 10,20 & 10,20 & 10,20 \\
Lower bound (LB) & $-10,-20$ & $-10,-20$ & $-10,-20$ & $-10,-20$ \\
Dimension (D) & & $13,17,21,23,27,29,37,41$ & \\
\hline
\end{tabular}




\begin{tabular}{|c|c|c|c|c|c|c|}
\hline Data set & PNN & Old ABC & Global ABCS & Guided ABC & New ABC & Probabilistic \\
\hline \multirow[t]{4}{*}{ BC (Original) 1992} & $9-3-2$ & 0.00032231 & 0.0003334 & 0.0001252 & 0.00000215 & for breast cancer \\
\hline & $9-6-2$ & 0.00078921 & 0.0008213 & 0.0001284 & 0.00000126 & \\
\hline & $9-9-2$ & 0.00071232 & 0.0004011 & 0.0001320 & 0.00000182 & Classmilativ \\
\hline & $9-11-2$ & 0.00070051 & 0.0000612 & 0.0002542 & 0.00000135 & \\
\hline \multirow[t]{4}{*}{ BC (Prognostic) 1995} & $9-3-2$ & 0.00060091 & 0.0003153 & 0.0001083 & 0.00000255 & \\
\hline & $9-6-2$ & 0.00006387 & 0.0000321 & 0.0002432 & 0.00000107 & 141 \\
\hline & $9-9-2$ & 0.00006513 & 0.0002122 & 0.0001123 & 0.00000013 & \\
\hline & $9-11-2$ & 0.00004162 & 0.0008872 & 0.0001011 & 0.00000365 & \\
\hline \multirow[t]{4}{*}{ BC (Diagnostic) 1995} & $9-3-2$ & 0.00010429 & 0.0002155 & 0.0001009 & 0.00000351 & \\
\hline & $9-6-2$ & 0.00001029 & 0.0006574 & 0.0001004 & 0.00000261 & \\
\hline & $9-9-2$ & 0.00001058 & 0.0006375 & 0.0008232 & 0.00000242 & \\
\hline & $9-11-2$ & 0.00001321 & 0.0004238 & 0.0007334 & 0.00000014 & Average MSE obtained \\
\hline \multirow[t]{4}{*}{ BC Coimbra Data set (2018) } & $9-3-2$ & 0.00009352 & 0.0004392 & 0.0008932 & 0.00000301 & during training PNN of \\
\hline & $9-6-2$ & 0.00010632 & 0.0000296 & 0.0000702 & 0.00001019 & $\mathrm{BC}$ data set on out of \\
\hline & $9-9-2$ & 0.00010521 & 0.0000241 & 0.0005972 & 0.00001008 & sample for \\
\hline & $9-11-2$ & 0.00020973 & 0.0000345 & 0.0004302 & 0.00001209 & classification \\
\hline
\end{tabular}

\begin{tabular}{|c|c|c|c|c|c|c|}
\hline Data set & PNN & Old ABC & Global ABCS & Guided ABC & New ABC & \\
\hline \multirow[t]{4}{*}{ BC (Original) 1992} & $9-3-2$ & 0.00045329 & 0.00059023 & 0.0008293 & 0.0007138 & \\
\hline & $9-6-2$ & 0.00089086 & 0.00182964 & 0.0007145 & 0.0007190 & \\
\hline & $9-9-2$ & 0.00079834 & 0.00098025 & 0.0007156 & 0.0006134 & \\
\hline & $9-11-2$ & 0.00079682 & 0.00016125 & 0.0006276 & 0.0004178 & \\
\hline \multirow[t]{4}{*}{ BC (Prognostic) 1995} & $9-3-2$ & 0.00069851 & 0.00081536 & 0.0007165 & 0.0007123 & \\
\hline & $9-6-2$ & 0.00008932 & 0.00063916 & 0.0007988 & 0.0009137 & \\
\hline & $9-9-2$ & 0.00007961 & 0.00094829 & 0.0007179 & 0.0009130 & \\
\hline & $9-11-2$ & 0.00005083 & 0.00099779 & 0.0004054 & 0.0005102 & \\
\hline \multirow[t]{4}{*}{ BC (Diagnostic) 1995} & $9-3-2$ & 0.00019878 & 0.00089055 & 0.0007081 & 0.0007190 & \\
\hline & $9-6-2$ & 0.00003405 & 0.00098445 & 0.0008022 & 0.0009139 & \\
\hline & $9-9-2$ & 0.00008911 & 0.00098124 & 0.0009234 & 0.0003178 & \\
\hline & $911-2$ & 0.00001982 & 0.00100928 & 0.0009313 & 0.0009178 & Average MSE of PNN \\
\hline \multirow[t]{4}{*}{ BC Coimbra Data set (2018) } & $9-3-2$ & 0.00021092 & 0.00012907 & 0.0018983 & 0.00052343 & testing phase of $\mathrm{BC}$ \\
\hline & $9-6-2$ & 0.00029812 & 0.00002196 & 0.0001778 & 0.00071077 & data set on out of \\
\hline & $9-9-2$ & 0.00036751 & 0.00002468 & 0.0009912 & 0.00091035 & sample for \\
\hline & $911-2$ & 0.00048293 & 0.00008485 & 0.0009301 & 0.00081455 & classification \\
\hline
\end{tabular}

were tested after training the PNN, with the best trained parameter values on the $\mathrm{BC}$ data set of various years. Again, the proposed new $\mathrm{ABC}$ algorithm succeeds in making less classification errors out of sample data of all types of $\mathrm{BC}$ data sets. The success rate obtained by the other three algorithms for $\mathrm{BC}$ classification results is given in Table 5 , where all learning algorithms have successfully classified the $\mathrm{BC}$ data set without any failing trials.

In addition, from the four table results, the PNN model along with proposed training algorithm played an important role getting high accuracy results in $\mathrm{BC}$ classification. The task shows that when the hidden nodes and the best network topology structure, MFE increased the accuracy, especially in the case of using new ABC and GABCS algorithms. The proposed and typical PNN learning techniques proved that the simulated and original $\mathrm{BC}$ indications are very close to each other except guided $\mathrm{ABC}$, which was not fully successful enough to perform a $\mathrm{BC}$ classification with lower numbers of MCN. Overall, the new implementation has successfully reached the minimum classification error with fewer iterations. 


\section{FEBE 1,2}

BC (Prognostic) 1995

BC (Diagnostic) 1995

Table 4.

BC Coimbra Data set (2018)

Average NMSE on out of sample data for $\mathrm{BC}$ classification

\begin{tabular}{llllll}
\hline Data set & PNN & Old ABC & Global ABC & Guided ABC & New ABC \\
\hline BC (Original) 1992 & $9-3-2$ & 0.00065149 & 0.0005902 & 0.000829 & 0.0007138 \\
& $9-6-2$ & 0.00108906 & 0.0018296 & 0.000715 & 0.0007019 \\
& $9-9-2$ & 0.00099654 & 0.0009803 & 0.000716 & 0.0006134 \\
BC (Prognostic) 1995 & $9-11-2$ & 0.00099502 & 0.0001613 & 0.000628 & 0.0004178 \\
& $9-3-2$ & 0.00089671 & 0.0008154 & 0.000717 & 0.0007123 \\
& $9-6-2$ & 0.00028752 & 0.0006392 & 0.000799 & 0.0009137 \\
BC (Diagnostic) 1995 & $9-9-2$ & 0.00027781 & 0.0009483 & 0.000718 & 0.0008913 \\
& $9-11-2$ & 0.00024903 & 0.0009978 & 0.000405 & 0.0005102 \\
& $9-3-2$ & 0.00039698 & 0.0008906 & 0.000708 & 0.0007219 \\
BC Coimbra Data set (2018) & $9-6-2$ & 0.00023225 & 0.0009845 & 0.000802 & 0.0009139 \\
& $9-9-2$ & 0.00028731 & 0.0009812 & 0.000923 & 0.0003178 \\
& $9-11-2$ & 0.00021802 & 0.0010093 & 0.000931 & 0.0009178 \\
& $9-3-2$ & 0.00040912 & 0.0001291 & 0.001898 & 0.0005233 \\
& $9-6-2$ & 0.00049632 & $2.196 \mathrm{E}-05$ & 0.000178 & 0.0007107 \\
& $9-9-2$ & 0.00056571 & $2.468 \mathrm{E}-05$ & 0.000991 & 0.0009135 \\
& $911-2$ & 0.00068113 & $8.485 \mathrm{E}-05$ & 0.00093 & 0.0008145
\end{tabular}

\begin{tabular}{lccccc}
\hline Data set & PNN & Old ABC $\%$ & Global ABC $\%$ & Guided ABC $\%$ & New ABC $\%$ \\
\hline BC (Original) 1992 & $9-3-2$ & 100 & 100 & 100 & 100 \\
& $9-6-2$ & 100 & 100 & 100 & 100 \\
& $9-9-2$ & 100 & 100 & 100 & 100 \\
BC (Prognostic) 1995 & $9-11-2$ & 100 & 100 & 100 & 100 \\
& $9-3-2$ & 100 & 100 & 100 & 100 \\
& $9-6-2$ & 100 & 100 & 100 & 100 \\
BC (Diagnostic) 1995 & $9-9-2$ & 100 & 100 & 100 & 100 \\
& $911-2$ & 100 & 100 & 100 & 100 \\
& $9-3-2$ & 100 & 100 & 100 & 100 \\
BC Coimbra Data set (2018) & $9-6-2$ & 100 & 100 & 100 & 100 \\
& $9-9-2$ & 100 & 100 & 100 & 100 \\
& $9-11-2$ & 100 & 100 & 100 & 100 \\
& $9-6-2$ & 100 & 100 & 100 & 100 \\
& $9-9-2$ & 100 & 100 & 100 & 100 \\
& $911-2$ & 100 & 100 & 100 & 100 \\
& & 100 & 100 & 100 & 100 \\
\hline
\end{tabular}

\section{Conclusion}

Training PNN in advance improved hybrid and new versions of $\mathrm{ABC}$ algorithms and has great potential for the classification of $\mathrm{BC}$ data sets. Here, the newly implemented algorithm $\mathrm{ABC}$, along with the old $\mathrm{ABC}$, a typical and improved version, has been proposed for $\mathrm{BC}$ classification tasks. The simulation results obtained from the abovementioned methods on the $\mathrm{BC}$ data set demonstrate that the proposed new $\mathrm{ABC}$ algorithm is able to be classified in the $\mathrm{BC}$ data set with a high accuracy and efficiently compared to other types of ABC-based algorithms due to the MFE criteria as well as others. Furthermore, the proposed new ABC, improved and typical $\mathrm{ABC}$ algorithms are successfully used to train PNN with optimal parameters and have remained stable with the high quantity of investigations and exploitation searching processes and can be successfully used to classify the various BC data sets. 


\section{References}

69372 Lyon CEDEX 08, F. I. 150 C. A. T (2020), The Global Cancer Observatory, IARC, 150 Cours Albert Thomas, 69372 Lyon CEDEX 08, France, available at: https:/gco.iarc.fr/.

Agarwal, M., Bohat, V.K., Ansari, M.D., Sinha, A., Gupta, S.K. and Garg, D. (2019), "A convolution neural network based approach to detect the disease in corn crop”, 2019 IEEE 9th International Conference on Advanced Computing (IACC), pp. 176-181, doi: 10.1109/IACC48062.2019.8971602.

Akay, B. and Karaboga, D. (2012), "A modified Artificial Bee Colony algorithm for real-parameter optimization”, Information Sciences, Vol. 192, p. 22.

Asri, H., Mousannif, H., Al Moatassime, H. and Noel, T. (2016), "Using machine learning algorithms for breast cancer risk prediction and diagnosis", Procedia Computer Science, Vol. 83, pp. 1,064-1,069, Elsevier, doi: 10.1016/j.procs.2016.04.224.

Ayer, T., Alagoz, O., Chhatwal, J., Shavlik, J. W., Charles, Kahn, E. and Burnside, E. S. (2010), Breast Cancer Risk Estimation with Artificial Neural Networks Revisited Discrimination and Calibration, available at: https://doi.org/10.1002/cncr.25081.

Bullinaria, J.A. and Al Yahya, K. (2014), "Artificial bee colony training of neural networks: comparison with back-propagation”, Memetic Computing, Vol. 6 No. 3, doi: 10.1007/s12293-014-0137-7.

Chen, X., Zhou, Y. and Luo, Q. (2014), “A hybrid monkey search algorithm for clustering analysis”, The Scientific World Journal, 938239, doi: 10.1155/2014/938239.

Chigbu, D.I., Loonawat, R., Sehgal, M. and Jain, P. (n.a.), "Cells hepatitis C virus infection: host-virus interaction and mechanisms of viral persistence", doi: 10.3390/cells8040376.

Gao, W., Liu, S. and Huang, L. (2012), "A global best artificial bee colony algorithm for global optimization”, Journal of Computational and Applied Mathematics. doi: 10.1016/j.cam.2012.01.013.

Ghazali, R., Hussain, A.J., Liatsis, P. and Tawfik, H. (2008), "The application of ridge polynomial neural network to multi-step ahead financial time series prediction", Neural Computing and Applications, Vol. 17, 3LB-Ghazali 2008, pp. 311-323, doi: 10.1007/s00521-007-0132-8.

Gray, E., Marti, J., Brewster, D.H., Wyatt, J.C. and Hall, P.S. (2018), "Independent validation of the PREDICT breast cancer prognosis prediction tool in 45,789 patients using Scottish Cancer Registry data”, British Journal of Cancer, Vol. 119 No. 7, pp. 808-814, doi: 10.1038/s41416-0180256-x.

Hu, J.W.S., Hu, Y.C. and Lin, R.R.W. (2012), “Applying neural networks to prices prediction of crude oil futures", Mathematical Problems in Engineering. doi: 10.1155/2012/959040.

Islam, M.M., Haque, M.R., Iqbal, H., Hasan, M.M., Hasan, M. and Kabir, M.N. (2020), "Breast cancer prediction: a comparative study using machine learning techniques", SN Computer Science, Vol. 1 No. 5, p. 29, doi: 10.1007/s42979-020-00305-w.

Karaboga, D. and Akay, B. (2009), "A survey: algorithms simulating bee swarm intelligence”, Artificial Intelligence Review. doi: 10.1007/s10462-009-9127-4.

Karaboga, D. and Gorkemli, B. (2011), "A combinatorial Artificial Bee Colony algorithm for traveling salesman problem”, INISTA 2011-2011 International Symposium on Innovations in Intelligent Systems and Applications. doi: 10.1109/INISTA.2011.5946125.

Karaboga, D., Akay, B. and Ozturk, C. (2007), "Artificial bee colony (ABC) optimization algorithm for training feed-forward neural networks", in Torra, V., Narukawa, Y. and Yoshida, Y. (Eds), Modeling Decisions for Artificial Intelligence: 4th International Conference, MDAI 2007, Kitakyushu, Japan, August 16-18, 2007. Proceedings, Berlin, Heidelberg, Springer Berlin Heidelberg, pp. 318-329, doi: 10.1007/978-3-540-73729-2_30.

Mao, W., Lan, H. and Li, H. (2016), “A new modified artificial bee colony algorithm with exponential function adaptive steps", in Zheng, Y. (Ed.), Computational Intelligence and Neuroscience, Hindawi Publishing Corporation, 9820294, doi: 10.1155/2016/9820294.

McCulloch, W.S. and Pitts, W. (1943), "A logical calculus of the ideas immanent in nervous activity", The Bulletin of Mathematical Biophysics, Vol. 5 No. 4, pp. 115-133, doi: 10.1007/BF02478259. 
FEBE 1,2

McNelis, P.D. (2005), "1 - introduction”, Neural Networks in Finance, Academic Press, Boston, p. 5, doi: 10.1016/B978-0-12-485967-8.50013-0.

Mernik, M., Liu, S.H., Karaboga, D. and Črepinšek, M. (2014), "On clarifying misconceptions when comparing variants of the Artificial Bee Colony Algorithm by offering a new implementation”, Information Sciences. doi: 10.1016/j.ins.2014.08.040.

Mui, U., Haley, C. and Tyring, S. (2017), "Viral oncology: molecular biology and pathogenesis", Journal of Clinical Medicine, Vol. 6 No. 12. doi: 10.3390/jcm6120111.

Naeem, S., Ali, A., Qadri, S., Khan Mashwani, W., Tairan, N., Shah, H., Fayaz, M., Jamal, F., Chesneau, C. and Anam, S. (2020), "Machine-learning based hybrid-feature analysis for liver cancer classification using fused (MR and CT) images", Applied Sciences, Vol. 10 No. 9, 3134, doi: 10. 3390/app10093134.

Nagao, Y., Kawaguchi, Y., Sugiyama, Y., Saji, S. and Kashiki, Y. (2003), "Relationship between mammographic density and the risk of breast cancer in Japanese women: a case-control study", Breast Cancer, Vol. 10 No. 3, pp. 228-233, doi: 10.1007/BF02966722.

Neapolitan, R.E. (2018), "Neural networks and deep learning”, Artificial Intelligence. doi: 10.1201/ b22400-15.

Nishiyama, K., Taira, N., Mizoo, T., Kochi, M., Ikeda, H., Iwamoto, T., Shien, T., Doihara, H., Ishihara, S., Kawai, H. and Kawasaki, K. (2020), "Influence of breast density on breast cancer risk: a case control study in Japanese women", Breast Cancer, Vol. 27 No. 2, pp. 277-283, doi: 10.1007/ s12282-019-01018-6.

Patrício, M., Pereira, J., Crisóstomo, J., Matafome, P., Gomes, M., Seiça, R. and Caramelo, F. (2018), "Using Resistin, glucose, age and BMI to predict the presence of breast cancer", BMC Cancer, Vol. 18 No. 1, p. 29, doi: 10.1186/s12885-017-3877-1.

Pervanidou, D., Vakali, A., Georgakopoulou, T., Panagiotopoulos, T., Patsoula, E., Koliopoulos, G., Politis, C., Stamoulis, K., Gavana, E., Pappa, S. and Mavrouli, M. (2020), "West Nile virus in humans, Greece, 2018: the largest seasonal number of cases, 9 years after its emergence in the country", Eurosurveillance. European Centre for Disease Prevention and Control (ECDC), Vol. 25 No. 32, doi: 10.2807/1560-7917.ES.2020.25.32.1900543.

Punitha, S., Al-Turjman, F. and Stephan, T. (2021), "An automated breast cancer diagnosis using feature selection and parameter optimization in ANN", Computers and Electrical Engineering, Vol. 90, pp. 106-958, doi: 10.1016/j.compeleceng.2020.106958.

Quist, J., Taylor, L., Staaf, J. and Grigoriadis, A. (2021), "Random forest modelling of high-dimensional mixed-type data for breast cancer classification”, Cancers. doi: 10.3390/cancers13050991.

Shah, H. and Ghazali, R. (2011), "Prediction of earthquake magnitude by an improved ABC-MLP", Proceedings - 4th International Conference on Developments in eSystems Engineering, DeSE 2011, doi: 10.1109/DeSE.2011.37.

Shah, H., Ghazali, R., Herawan, T., Rahman, S.U. and Khan, N. (2016), "Chapter 14 - swarm basedartificial neural system for human health data classification A2 - Al-Jumeily, Dhiya", in Hussain, A., Mallucci, C. and Oliver, C. (Eds), Applied Computing in Medicine and Health, Morgan Kaufmann, Boston, pp. 287-309, doi: 10.1016/B978-0-12-803468-2.00014-X.

Society, A.C. (2019), Cancer Facts and Figures Report 2019, American Cancer Society, Atlanta, GA.

Soklic, M.Z.M. (1994), UCI Repository of Machine Learning Databases, Institute of Oncology University Medical Center Ljubljana, Yugoslavia.

Specht, D.F. (1992), "Enhancements to probabilistic neural networks", [Proceedings 1992] IJCNN International Joint Conference on Neural Networks, Vol. 1, pp. 761-768, doi: 10.1109/IJCNN.1992. 287095.

Sung, H., Ferlay, J., Siegel, R.L., Laversanne, M., Soerjomataram, I. and Jemal, A. (2021), “Global cancer statistics 2020: GLOBOCAN estimates of incidence and mortality worldwide for 36 cancers in 185 countries", doi: 10.3322/caac.21660. 
Supriya, M. and Deepa, A.J. (2020), "A novel approach for breast cancer prediction using optimized ANN classifier based on big data environment", Health Care Management Science, Vol. 23 No. 3, pp. 414-426, doi: 10.1007/s10729-019-09498-w.

Suruchi, C. (2016), "Application of genetic algorithm and back propagation neural network for effective personalize web search-based on clustered query sessions", International Journal of Applied Evolutionary Computation (IJAEC), Vol. 7 No. 1, pp. 33-49, doi: 10.4018/IJAEC. 2016010103.

Tairan, N., Shah, H. and Aleryani, A. (2019), "Prediction of crude oil prices using hybrid guided best-

Probabilistic neural network for breast cancer classification so-far honey bees algorithm-neural networks", International Journal of Advanced Computer Science and Applications, Vol. 10 No. 5, doi: 10.14569/IJACSA.2019.0100540.

Teodorović, D. (2009), "Bee colony optimization (BCO)", Studies in Computational Intelligence. doi: 10. 1007/978-3-642-04225-6_3.

Vaisitti, T., Arruga, F. and Ferrajoli, A. (2020), "Chronic lymphocytic leukemia”, Cancers, Vol. 12 No. 9, pp. 1-4, doi: 10.3390/cancers12092504.

Waheeb, W., Ghazali, R. and Herawan, T. (2016), "Ridge polynomial neural network with error feedback for time series forecasting", PLOS One, Vol. 11 No. 12, p. e0167248, doi: 10.1371/ journal.pone.0167248.

World Health Organization (2020), "WHO report on cancer: setting priorities, investing wisely and providing care for all", available at: https://apps.who.int/iris/handle/10665/330745.

Yang, X. (2010), Nature-Inspired Metaheuristic Algorithms, Nature-Inspired Metaheuristic Algorithms, 2nd ed, doi: 10.1016/B978-0-12-416743-8.00005-1.

Yang, X.S. (2014), "Swarm intelligence based algorithms: a critical analysis", Evolutionary Intelligence. doi: 10.1007/s12065-013-0102-2.

Zhang, Y., Wang, S. S., Ji, G., ... Taylor, M. M. (2015). “1 - Introduction”, Applied Soft Computing Journal, pp. 1-10, doi: 10.1016/B978-012485967-8.50001-4.

Zhu, G. and Kwong, S. (2010), "Gbest-guided artificial bee colony algorithm for numerical function optimization”, Applied Mathematics and Computation, Vol. 217 No. 7, pp. 3,166-3,173, doi: 10. 1016/j.amc.2010.08.049.

\section{Corresponding author}

Habib Shah can be contacted at: habibshah.uthm@gmail.com

For instructions on how to order reprints of this article, please visit our website:

www.emeraldgrouppublishing.com/licensing/reprints.htm

Or contact us for further details: permissions@emeraldinsight.com 